\title{
Is urban gardening safe? Trace element concentrations and exposure risk measured from over 15,000 soils from 3,000 Australian gardens
}

\author{
TAYLOR, M.P., ${ }^{1}$ ISLEY, C.F., ${ }^{1}$ LIU, X., ${ }^{1,3}$ FRY, K., ${ }^{1}$ \\ Gillings, M.M., ${ }^{1}$ Rouillon, M., ${ }^{1}$ SoltAni, N.S., ${ }^{1}$ \\ Gore, D.B., ${ }^{1}$ FiliPPELli, G. ${ }^{2}$
}

${ }^{1}$ Macquarie University, Australia, mark.taylor@mq.edu.au ${ }^{2}$ Indiana University-Purdue University Indianapolis, USA

${ }^{3}$ China University of Geosciences, Beijing, China

Urban vegetable gardening is increasing in popularity worldwide but this is often occuring in contaminated soils. Home owners typically have limited knowledge of potential contamination and do not have access to affordable soil trace element analysis. To address this gap, we devised the public science initiative 'VegeSafe' in 2013 to empower the Australian community to better understand contaminants in their home gardens, address any potential health risks and promote safe gardening practices.

This study presents data on trace element concentrations (As, $\mathrm{Cd}, \mathrm{Cr}, \mathrm{Cu}, \mathrm{Mn}, \mathrm{Ni}, \mathrm{Pb}$ and $\mathrm{Zn}$ ) from 15,313 soil samples from 3,196 Australian homes. Participants provided samples and associated metadata via post to Macquarie University. Soil samples were analysed using portable X-Ray fluorescence spectrometry. Geospatial techniques were used to ascertain where soil contamination exceeded Australian residential guidelines. Uptake of potentially toxic trace elements into vegetables was calculated using literature values. Potential carcinogenic and non-carcinogenic health risks associated with soil $\mathrm{As}, \mathrm{Cu}, \mathrm{Mn}, \mathrm{Ni}, \mathrm{Pb}$ and $\mathrm{Zn}$ concentrations were determined using US EPA modelling.

Lead was the element that most frequently exceeded Australian guidnelines for residential gardens $(300 \mathrm{mg} / \mathrm{kg}$ ) in the inner city areas of Sydney, Melbourne and Brisbane. Mean soil Pb concentrations were 221.5 (95 \% CI: 213.6229.6) with $20.4 \%$ of all samples $>300 \mathrm{mg} / \mathrm{kg}$. For other trace elements, less than $4 \%$ of samples exceeded Australian guideline values. Non-carcinogenic risk for children exposed to soil $\mathrm{Pb}$ and $\mathrm{Mn}$ exceeded tolerable limits in nine regions of Sydney, Melbourne and Brisbane, while excessive carcinogenic risk was rare. Uptake of $\mathrm{Pb}$ by garden produce is of concern with $20 \%$ of vegetable gardens estimated to be producing food that exceeds Australian and World Health Organization criteria for $\mathrm{Pb}$ content (typically $0.1 \mathrm{mg} / \mathrm{kg}$ ).

Although trace element concentrations from $80 \%$ of Australian gardens are unlikely to pose a health risk, the prevalence of $\mathrm{Pb}$ in inner city gardens suggests that specific populations are at a greater risk. 